\title{
À procura da intimidade: formas de oração em língua vernácula na França dos séculos XIV e XV
}

Letícia Gonçalves Alfeu de Almeida ${ }^{1 *}$

${ }^{1}$ Universidade Estadual Paulista Júlio de Mesquita Filho, Franca / SP - Brasil

\section{RESUMO}

Este artigo analisa uma série de textos de oraçáo compostos em língua francesa nos séculos XIV e XV e que ensinaram a um público laico modalidades devocionais consideradas "interiores”, isto é, de inspiração monástica, fundadas na leitura, na meditação e na oração privada. Trata-se de explorar como tais textos redigidos por clérigos e distintos dos livros de horas - que nesse período ainda privilegiavam o latim - veicularam um programa de vida virtuosa para leigos interessados em dedicar-se mais integralmente à oração em seu cotidiano doméstico. Importa interrogar o valor desses ensinamentos num momento de tensōes geradas pelo Cisma papal que dividiu a Igreja entre Roma e Avinhão de 1378 a 1417, e igualmente pela reprovação clerical dos excessos devocionais vindos de figuras que então buscavam formas mais íntimas e diretas de diálogo com Deus, com frequência manifestas em visóes, êxtases e estigmas, bem como no menosprezo dos sacramentos.

Palavras-chave: oração; devoção laica; França medieval; língua vernácula; intimidade.

\section{In search of intimacy: forms of prayer in vernacular language in fourteenth and fifteenth-century France}

\section{ABSTRACT}

This article analyzes a series of French prayer texts composed in the fourteenth and fifteenth centuries. These texts taught the lay public devotional modalities considered "internal," that is, inspired by monastic practices based on reading, meditation and private prayer. It is worth exploring how such texts, which were written by clergymen and differed from the Books of Hours - which in that period still privileged Latin - presented a program of

DOI: http://dx.doi.org/10.1590/2237-101X02104512

Artigo recebido em $1^{\circ}$ de abril de 2019 e aceito para publicaçáo em 2 de janeiro de 2020.

* Professora da Universidade Estadual Paulista Júlio de Mesquita Filho / Faculdade de História, Direito e Serviço Social, Franca / SP - Brasil. E-mail: leticiaalfeudealmeida@gmail.com. ORCID: https://orcid. org/0000-0002-3404-0276. 
virtuous life for lay people interested in more fully dedicating themselves to prayer in their daily life. It is important to consider the value of such teachings in the context of tensions generated by the papal schism - which divided the Church between Rome and Avinhão from 1378 to 1417 - and the clerical reprobation of devotional excesses coming from those who were then seeking more intimate and direct ways of talking with God, such as visions, ecstasies and stigmata, and the disregard of sacraments.

Keywords: prayer; lay devotion; Medieval France; vernacular language; intimacy.

\section{En la búsqueda de la intimidad: formas de oración en lengua vernácula en la Francia de los siglos XIV y XV}

\section{RESUMEN}

Este artículo analiza una serie de textos de oración compuestos en lengua francesa en los siglos XIV y XV y que enseñaron a un público laico modalidades devocionales consideradas "interiores", o sea, de inspiración monástica fundadas en la lectura, en la meditación y en la oración privada. Se pretende explorar cómo estos textos redactados por clérigos y distintos de los libros de horas -que en este periodo todavía privilegiaban el latín-, transmitían un programa de vida virtuosa para laicos interesados en dedicarse más integralmente a la oración en su cotidiano doméstico. Importa examinar el valor de esos enseñamientos en un momento de tensiones generadas por el cisma papal que dividió la Iglesia entre Roma y Avińón de 1378 a 1417, e igualmente por la reprobación clerical de los excesos devocionales procedentes de figuras que en ese entonces buscaban formas más íntimas y directas de diálogos con Dios, con frecuencia manifestadas en visiones, éxtasis y estigmas, así como en el menosprecio a los sacramentos.

Palabras clave: oración; devoción laica; Francia medieval; lengua vernácula; intimidad.

\section{Introdução}

No início do século XV, quando o Cisma da Igreja já se arrastava há duas décadas (STUMP, 2009, p. 395-442), intensificando o ímpeto das autoridades temporais e eclesiásticas pela sua solução, o teólogo chanceler da Universidade de Paris, Jean Gerson (13631429), comunicava em uma de suas correspondências privadas a preocupação com a grande "necessidade de educação do povo e a solução das questôes morais em nossos tempos". Conclamava, assim, os teólogos da universidade a deixarem a natureza somente especulativa de 
seu ofício e a tomarem para si o papel de condutores morais e espirituais da Cristandade em tempos de crise. O letrado desferia pesadas críticas aos seus pares, que, segundo ele, estavam mais centrados no estudo e nas operaçóes intelectuais por si mesmas, em prejuízo do comprometimento devocional e moral, considerados mais necessários diante de táo delicado contexto. Concluía que, "em tal situação crítica e entre tantos perigos para as almas, dificilmente se pode[ria] estar satisfeito em brincar com matérias [...] que são completamente supérfluas", referindo-se aos estudos teológicos sem efeitos para a conversão e a salvação de todos (GERSON, 1998, p. 174). ${ }^{2}$

Desde 1399 no cargo de chanceler ${ }^{3}$ (GIEYSZTOR, 1996, p. 128) da mais célebre universidade do Ocidente cristáo, Jean Gerson enfrentava os impasses políticos que marcaram os reinados de Carlos VI e Carlos VII e envolviam aquela instituiçáo na trama de alianças entre os poderes temporais e eclesiásticos (GERSON, 1998, p. 18). ${ }^{4} \mathrm{O}$ estabelecimento da corte papal em Avinhão de 1309 a 1377, em que a proximidade com o rei francês e a vida opulenta dos cardeais era censurada, culminara na divisão que submeteu a Igreja à gerência antagônica de dois patriarcas, eleitos pelos cardeais leais aos reis franceses e por aqueles partidários de Roma, respectivamente (ROLLO-KOSTER; IZBICKI, 2009, p. 70-71). Os teólogos universitários empenhados em restabelecer a unidade da Igreja por meio de um acordo entre as partes frustraram-se com a intransigência orgulhosa de ambos os pontífices, que não acataram a proposta de renúncia apresentada em 1395, prolongando as tensóes (PASCOE, 1973, p. 11)..$^{5}$ O Cisma fomentava, nesse sentido, a percepção de um contexto de triunfo do pecado, especialmente em referência aos vícios dos eclesiásticos, que se afastavam do modelo dos apóstolos. Tal panorama incutia no doutor de Paris uma convicção: a de que, naquele momento, mais importantes do que a erudição e o conhecimento teórico eram a fé, a piedade e a afetividade, requisitos que considerava ausentes nos teólogos e eclesiásticos e

\footnotetext{
${ }^{2}$ Tradução minha. No original: "For the honor of God it should be considered carefully how great is the need for the education of the people and the solution of moral questions in our times. And so one must believe that in such a critical situation and amid do many dangers to souls, one can hardly be satisfied with playing about, not to speak of engaging in fantasies, with matters that are wholly superfluous".

${ }^{3}$ Em Paris, o chanceler do capítulo de Notre-Dame geria as escolas universitárias e encarregava-se de conceder oficialmente os graus acadêmicos. O seu papel variava nas diversas universidades, onde geralmente desempenhava a função de representante oficial do bispo. Há no período um reforço do papel do chanceler nas universidades pelos reis, função que era distinta da dos reitores, eleitos internamente.

${ }^{4}$ Nesses reinados, além da devastação causada pela guerra com a Inglaterra, surgiram os conflitos armados entre armagnacs e bourguignons, partidários dos duques da Borgonha e de Orléans, primo e irmáo do rei Carlos VII, respectivamente, que disputavam o poder diante da incapacidade do soberano considerado louco. O Cisma traria dificuldades especialmente à Universidade, pois, chamada "filha do rei", devia fidelidade ao monarca e ao seu pontífice aliado.

${ }^{5}$ Com a morte do Papa de Avinhão, Clemente VII (1378-1394), em 1394, os teólogos vislumbraram uma chance de solucionar o impasse, porém, o pontífice sucessor, Bento XIII (1394-1424), bem como o romano, Bonifácio IX, não acataram a proposta apresentada por membros da Universidade de Paris (via cessionis), que exigia a dupla renúncia. A persistência de ambos se estendeu até 1417, quando finalmente o Concílio de Constança põe fim ao Cisma.
} 
encontrava nas pessoas chamadas de "simples", que "têm fé" mesmo sem instrução e iniciação nos conhecimentos teológicos.

A oração, definida como prática afetiva por excelência, aparecia, portanto, nos escritos do chanceler como remédio à falta de piedade e aos vícios observados naqueles tempos: "a oração não é nada além do afeto humilde e devoto dirigido finalmente a Deus" (GERSON, 1960, v. VII, p. 238), ensinava no tratado La Mendicité Spirituelle, de 1401, endereçado aos "simples” em língua vernácula (NAGY, 2006, p. 444, 446, 455, 463; CASAGRANDE, 2013, p. 115). ${ }^{6} \mathrm{O}$ teólogo destacava o valor das gentes "de devoçáo" que se dedicavam por completo à oração, também chamadas de "contemplativas" - não necessariamente monges ou religiosos -, que seriam táo responsáveis por atrair a graça de Deus como as pessoas ativas, voltadas às obras de misericórdia corporais. Os que rezam "são úteis como os olhos são ao corpo" e, por meio de sua proximidade com Deus, conseguem dons para todos; por isso, "mais proveitosa a toda a Igreja [é] a oração devota de um contemplativo do que [as obras de] cem [pessoas] que levam a vida ativa e socorrem as necessidades corporais" (GERSON, 1960, VII, p. 36). ${ }^{7}$ Curiosamente, em um tempo em que o reino da França enfrentava profundas tensóes não somente espirituais e religiosas, mas também materiais, com a guerra, a violência, a pestilência e a pobreza (CHIFFOLEAU, 1980, p. 325-37; CHIFFOLEAU, 1979), um clérigo renomado e influente defendia a superioridade da oração, da contemplaçáo (BROWN, 1987, p. 171; FISHER, 2006, p. 217; PETRY, 1957, p. 17; HARRINGTON, 2004, p. 8-9) ${ }^{8}$ e do recolhimento espiritual em detrimento das açóes "corporais" (SCHMITT, 2014, p. 306), ${ }^{9}$ exteriores e caritativas, e enaltecia os exemplos de gente devota.

\section{A oração como refúgio e remédio}

A oração constituía para o chanceler de Paris uma forma de refúgio perante os males do tempo. Às suas amizades mais próximas, envolvidas ao seu lado na querela do Cisma, como o ex-chanceler Pedro D’Ailly, recomendava “o alimento da devoção interior” (GER-

\footnotetext{
${ }^{6}$ Tradução minha. No original: "oraison n'es fors humble et devote affection ramenee finablement a Dieu”. A definição faz referência a Hugo de São Victor, para quem a oração não é mais uma fala, mas um sentimento, uma devoção.

${ }^{7}$ Tradução minha. No original: "Et sont comme les yeuls du corps"; Plus pourfitte a toute l'eglise l'oroison devote d'un contemplatif que ne font cent et cent que mainent vie active pour secourir aux necessités corporelles".

${ }^{8}$ Gerson empregava os termos "teologia mística" e "contemplação" como sinônimos. O primeiro era usado por teólogos como Hugo de Balma, no século XIV, enquanto Tomás de Aquino ou Boaventura recorreram à palavra "contemplação". O uso desta consolida-se com o influxo das traduçóes do De mystica theologia de Dionísio, após o século XII, para referir ao contato direto e interior com Deus e o processo que o conduz.

${ }^{9} \mathrm{O}$ "corpo" é a parte material e perecível da "pessoa", criada por Deus, e opóe-se à "alma", também criada, porém imortal.
} 
SON, 1998, p. 260). ${ }^{10}$ Da mesma maneira que aconselhava seus colegas da universidade, Gerson procurava direcionar a atenção dos fiéis simples para as necessidades espirituais e não apenas corporais de toda a comunidade cristá, destacando o potencial inestimável da contemplação e da oração, que podiam e deviam ser praticadas por todos e não apenas pelos religiosos, prelados ou teólogos como ele. $\mathrm{O}$ chanceler avançaria ainda mais em sua defesa da oração e do recolhimento devocional ao compor, especificamente para os simples e leigos, textos de iniciação à contemplação, prática monástica que tratava da experiência momentânea de suspensão dos sentidos e união da alma a Deus, conduzida pela oração e pela meditação. Esse assunto foi apresentado a esse público a partir de ensinamentos simplificados em língua vernácula, nomeadamente nos textos Montaigne de Contemplation e La Mendicité Spirituelle.

Em 1401, ao escrever em francês para os simples o texto que definiu como o seu "tratado de oração", o citado La Mendicité Spirituelle, Jean Gerson retomava uma pergunta corrente (HASENOHR, 2015, p. 66): "Por que dizem os salmos as gentes que não os entendem [...], pois não sabem nada do latim?" (GERSON, 1960, v. VII, p. 238) ${ }^{11}$ Resguardando a velha prática de ensinar e proferir as oraçôes na língua latina, o teólogo explica que o fato de os fiéis não compreenderem o que diziam em suas preces não impedia a comunicação com Deus, desde que a intenção e o afeto sinceros os motivassem. Ademais, "as pessoas simples iletradas dizem as oraçôes que não sabem para fazer reverência a Deus, louvar ou agradecer as palavras sagradas reveladas [...] ou para obedecer à Igreja e ao confessor" (GERSON, 1960, VII, p. 240). ${ }^{12}$ A questão retomada pelo teólogo fazia sentido num período em que, em diversas plagas do Ocidente, se começavam a elaborar escritos devocionais nas línguas vernáculas, de conteúdo variado, trazendo ensinamentos sobre as maneiras de rezar, bem como fórmulas para uso pessoal, conforme a uma crescente reivindicação dos laicos (LE GOFF; SCHMITT, 2006, p. 237-252) ${ }^{13}$ por maneiras mais pessoais, afetivas e íntimas de diálogo com o sagrado (CHIFFOLEAU, 2011, p. 104-117; VAUCHEZ, 1987, p. 10). ${ }^{14}$ Tais escritos de devoçáo diferiam dos livros de horas dos nobres, cuja leitura, encorajada pela

\footnotetext{
${ }^{10}$ Tradução minha. No original: "the nourishment of interior devotion".

${ }^{11}$ Tradução minha. No original: "Pourquoy on dit le sautier par gens qui ne l'entendent mie [...] ou souvent la personne n'entendra mie ce quelle dit car elle ne saura riens de latin".

12 Traduçâo minha. No original: "[...] simples gens sans lettres dient aucune fois les oroisons qu'elles ne scevent, car c'est pour faire reverence a Dieu ou pour le loer et regracier par les sainttes et sacrees paroles revelles [...] ou pour obeir a l'esglise ou a son confesseur [...]".

${ }^{13}$ A distinção clérigos e leigos aprofundou-se com a Reforma Gregoriana, no século XI, que reafirmou o celibato como distintivo do sacerdócio e elevou a dignidade do casamento e da reproduçáo como encargos dos laicos. Essa distinçáo de ordem jurídica, social, sexual e espiritual envolvia outras fronteiras da sociedade, como a entre homens e mulheres, letrados e iletrados, casados e celibatários. Do século XIII ao XV, os leigos investem em assuntos e ofícios próprios dos clérigos, como a teologia, a pregação e a escrita.

${ }^{14}$ André Vauchez assinala que a maior participação e inclusão dos leigos nos projetos religiosos após o século XII desenvolveu-se no sentido de uma crescente apropriação dos modelos monásticos, culminando, nos séculos XIV e XV, num fenômeno de imitação das formas de piedade clericais.
} 
Igreja como prática dos bons cristãos, ainda se fazia em latim, com base no ofício monástico e com reduzido espaço para a língua vernácula (HASENOHR, 2015, p. 65-66). ${ }^{15}$

A defesa da validade da prática da oração em latim para os leigos movidos apenas pela piedade genuína não impediria, portanto, que autoridades como o próprio Gerson, preocupadas com as lacunas e com a fragilidade da pastoral francesa do período, apostassem não apenas no fortalecimento da pregação, mas significativamente na difusão escrita dos ensinamentos religiosos, com a composição de tratados de oração em francês. $\mathrm{O}$ chanceler determinava que, naquele tempo de tribulaçóes, da mesma maneira que "em tempos de pestes a faculdade de medicina compôs um pequeno tratado para informar as pessoas", deveria ser elaborado um breve texto "sobre os principais pontos de nossa religiáo, e especialmente em seus preceitos, para a instrução das pessoas ignorantes" (GERSON, 1998, p. 174). ${ }^{16} \mathrm{Tal}$ desígnio cumpria o escrito de 1401-1402, intitulado A.B.C. des simples gens, que obteve larga fortuna no Ocidente ao ser traduzido para outras línguas e que se dirigia a todos, clérigos e leigos, "pequenos e grandes, meninos e meninas e outras pessoas simples", elencando como fundamentais o aprendizado das oraçóes principais, o Pai Nosso, a Ave Maria e o Credo, ao lado dos mandamentos, das virtudes e dos dons do Espírito Santo, entre outros pontos da fé definidos como obrigatórios para todo fiel (GERSON, 1960, v. VII, p. 155). ${ }^{17}$

No reino francês, o Cisma contribuía para o enfraquecimento da ação dos clérigos no âmbito local ou paroquial, em decorrência da polarização política que minava não apenas a viabilidade administrativa, mas também a confiança dos fiéis nas autoridades eclesiásticas (DAILEADER, 2009, p. 96; BLUMENFELD-KOSINSKI, 2006, p. 5-7). Com isso, preocupaçôes similares às de Gerson também impulsionavam outros letrados a compor textos em língua vernácula para os leigos - ou na tradução de escritos latinos -, no intuito de minimizar essas lacunas, contendo as oraçôes e os preceitos básicos da fé. O Doctrinal de Sapience, concebido pelo arcebispo de Reims, Guy de Roye (1345-1409), é descrito no prefácio como "livro em francês e de grande proveito e edificaçáo", feito "para a salvaçáo das almas de todo o povo, e em especial das simples pessoas laicas", e trazia os artigos da fé católica, os julgamentos de Deus, as penas do inferno, as alegrias do paraíso, a paixáo de Cristo, apresentados "brevemente e de forma simples, para a gente simples" (GUY DE ROY, 1485, p. 1). ${ }^{18}$ Quando se escrevia a este público não versado no latim, era, em suma, para instruir sobre

\footnotetext{
${ }^{15} \mathrm{O}$ aparecimento dos volumes em francês ocorre apenas em meados do século XVI.

${ }^{16}$ Tradução minha. No original: "[...] as once in the time of plagues the faculty of medicine composed a little treatise in order to inform people, similarly it might be done through the faculty of theology or at the order of someone that a little treatise be made on the main point of our religion, and specially on its precepts for the instruction of uneducated people".

${ }^{17}$ Tradução minha. No original: "Entendez tous, petiz et grans, filz et filles et aultres gens simples".

${ }^{18}$ Tradução minha. No original: "liure en francoys est de tresgrant proffit et edification [...] pour le salut de son ame et des ames de tous son peuple et dit par especial des simples gens lays pour lesquelz ledit liure a este fait especialement et ordonne"; "briefuemet et a grossement pour les simples gens par ledit reuerend pere ou les subgets bon conseil leur en sera donne et declaracion souffisante qui len vouldra auoir".
} 
um conjunto de preceitos fixos, por meio de fórmulas, tópicas e divisóes muito semelhantes e repetitivas, como no texto anônimo Bons enseignemens pour endoctriner simple gens, que, feito para a "salvação das almas do simples povo cristão e para mostrá-los de forma básica" o conteúdo da fé, ${ }^{19}$ continha a lista dos mandamentos, dos pecados segundo as partes do corpo; as descriçōes do inferno e do paraíso; a maneira de confessar e considerações sobre as três oraçôes básicas - conteúdo muito semelhante ao de textos vernáculos que circulavam em outros reinos cristáos.

Difundia-se, por conseguinte, nos séculos XIV e XV, um tipo específico de texto edificante em língua vernácula, de caráter básico e sumário a respeito das principais obrigaçôes de todo fiel no âmbito privado e público, quanto aos pecados, aos sacramentos e às oraçóes, estando Jean Gerson na dianteira da confecção e da difusão desse tipo de manual para uso de curas e fiéis, não somente do reino da França - dadas as numerosas traduçóes dos escritos desse letrado -, com uma linguagem simples e cotidiana. Os escritos sobre a oração em francês acompanhavam, desse modo, essa iniciativa mais ampla de compor textos em língua vernácula para apurar a instrução básica dos leigos nos assuntos da fé. No entanto, ao lado dos tópicos da fé cristã listados como básicos e obrigatórios pelos prelados que então começavam a redigir seus textos na língua do povo - como os sacramentos, os pecados, os artigos de fé, os mandamentos -, alguns escritos elencavam temas menos familiares ao público leigo. Esses textos, por sua vez, apresentavam um caráter mais devocional, ascético, espiritual ou místico (KENNEY, 2013, p. 93-127) ${ }^{20}$, nos moldes monásticos, em vez de apenas moral, catequético e sacramental. Sugeriam uma devoção interior (AUGUSTINE, 2002, p. 61; VON MOOS, 1995, p. 131-140) ${ }^{21}$ fundada na leitura, na meditação e na oração, e abriam, portanto, o caminho para o público laico aprimorar sua devoção pessoal no âmbito privado - especialmente a partir dos tratados de Gerson mencionados acima, voltados aos "simples" e às mulheres. ${ }^{22}$

\footnotetext{
${ }^{19}$ BNF, Département des manuscrits, Ms. Français 926. Tradução minha. No original: "pour le salut des ames du simple peuple crestien et pour eulx monstrer en gros la témeur de ntre foy et pour sauoir ce qui Dieu nous cómande et deffens".

${ }^{20}$ Relativo à teologia mística (da ordem do oculto e do indizível) e à contemplação. Para os pensadores medievais, é o momento do contato direto da alma com Deus, por meio de uma suspensáo das percepçóes sensíveis e da conexão da alma com a temporalidade, caracterizando um estado de êxtase em que se contempla a eternidade, alcançado por uma ascese específica, dividida em etapas progressivas.

${ }^{21}$ Com base na noção pauliniana, aprofundada por Agostinho, o homem é composto de um interior, onde deve buscar Deus, e de um exterior. A devoção supóe uma atitude de interiorização.

${ }^{22}$ A devoção interior amparada na escrita vernácula despontava também entre os "devotos" flamengos, comunidades de leigos e religiosos que cultivavam a introspecção e a leitura, difundindo-se na França a partir de 1380 e também em regióes onde a produção livresca foi menos próspera e a chegada da imprensa, tardia, como a Península Ibérica. A respeito dos primeiros, ver a obra de R. R. Post, The modern devotion, discriminada nas referências deste artigo. Sobre a oração silenciosa e privada nos textos peninsulares, sugiro a recente edição Guias dos costumes cristãos, organizada por Leandro A. Teodoro.
} 


\section{Anseios dos laicos por uma vida de plena devoção}

$\mathrm{O}$ texto anônimo Avisements sur le fait du gouvernement quotidien, feito no século XV para os laicos que desejassem aprofundar sua devoção, constituiu um desses guias morais e espirituais, com orientaçóes sobre o governo dos pensamentos, da fala, do corpo e das ocupaçôes cotidianas, tendo em vista uma vida mais voltada para a oração e para o recolhimento devocional. O texto propunha que o fiel se distanciasse o mínimo possível das ocupaçóes "espirituais" - exceto em caso de mulheres casadas e serviçais -, e ensinava a rezar: "Quando se está em oração, que se coloque todo esforço em espantar do seu coração todos os pensamentos mundanos estranhos a Deus e que se considere a quem fala, a Deus, e que ele está presente". ${ }^{23}$ Além de orientar a disposição emocional do fiel em relação ao mundo, recomendava a maneira reverenciosa e humilde de se dirigir ao Criador $^{24}$. Diferentes dos livros de horas e das oraçóes básicas aprendidas no âmbito geral e mais rudimentar da catequese, textos desse tipo apresentavam, além das mencionadas três orações principais, outros modelos de prece, mais complexos e para circunstâncias mais específicas. Esses escritos listavam, em suma, as diretrizes de um programa de vida integralmente voltada para a devoção e para oração. Ao lado de consideraçôes sobre como se portar em oração ou sobre os benefícios da prece para a alma, ou explicaçóes mais elaboradas das asserçôes do Pai Nosso e da Ave Maria, ajuntavam-se fórmulas em primeira pessoa, para serem praticadas em silêncio ou pela voz, em local retirado das movimentaçóes terrenas.

Exemplos dessas orientaçóes para o cotidiano encontram-se nos comentários bíblicos do século XV sobre o Carmen de muliere forti, como o livro de François Le Roy, da ordem religiosa de Fontevraud, Le livre de la femme forte et vertueuse, impresso por Simon Vostre em Paris. Esse texto apresentava oraçôes para cada versículo e exprimia um diálogo pessoal, íntimo e afetivo com Deus: "Meu doce e benigno salvador, [...] de todo o meu coraçáo eu te suplico e peço que queira me conceder as virtudes acima citadas [...] para que pela tua graça eu possa ser a mulher forte e virtuosa de quem fala Salomáo" (LE ROY, s/d). ${ }^{25} \mathrm{O}$ escrito destinava-se ao mesmo tempo "a pessoas religiosas e outras gentes de devoção", ${ }^{26}$ sugerindo a transposição de modalidades devocionais monásticas para o cotidiano de certos grupos devotos laicos. No mesmo sentido, o comentário da referida passagem bíblica elaborado anteriormente pelo teólogo e bispo de Meaux, Jean de Bory (- 1432) - também confessor

\footnotetext{
${ }^{23}$ BNF, Département des manuscrits, Ms. Français 13204, f. 161. Tradução minha. No original: "quant on vient a oraison quon mectre peine de tout son pouoir de merueille son cuer de toutes pensees mondaines et estranges dedieu et quon regarde deuant qui on parle cest adieu quon pense quil est present".

${ }^{24}$ BNF, Département des manuscrits, Ms. Français 13204, f. 161.

${ }^{25}$ Tradução minha. No original: "Mon doulx et begnin sauueur docteur de parfonde humilite, [...] de tout mó cueur te suplie et requier quil te plaise me dōner et octroyer les vertus dessusdicte [...] affin que par ta grace ie puisse estre la forte et vertueuse femme de laq uelle salomon a dit".

${ }^{26}$ Tradução minha. No original: "utile et prouffitavle a psonnes religieuses et autres gens de devotion".
} 
de Catarina da França e tutor dos filhos de Carlos VI -, Exposition du Carmen de muliere forti, assinalava que se dirigia "mais especialmente à instrução das mulheres de religiáo ou de mulheres que vivem em castidade fora do casamento e que se entregam ao serviço de Deus em seu coração" ${ }^{27}$ referindo-se às mulheres que escolhiam levar uma vida devota doméstica, sem votos religiosos formais, mas à semelhança das monjas.

No reino da França dos séculos XIV e XV, tornava-se cada vez mais comum os leigos, em especial mulheres, sobretudo solteiras e viúvas, optarem por uma vida de ascese e recolhimento devocional de inspiração monástica em seus próprios lares, seguindo uma disciplina devota sem se vincular a uma ordem religiosa, mas geralmente com a supervisão de um mentor clérigo, na maioria das vezes o próprio confessor (WEBB, 2007, p. x, 119-121). A escolha por tal forma de vida ambígua, entre o estatuto religioso e laico, não constituía uma singularidade francesa, já que se alastrava em diversos pontos da Cristandade, simultaneamente, entre grupos sociais diversos. No reino da França, esse modo de vida ampliava-se tanto no que dizia respeito aos fiéis que praticavam a devoção em suas próprias casas, sob orientaçáo do diretor espiritual clérigo (CASAGRANDE, 1990, p. 139), quanto aos que adentravam grupos devocionais laicos mais autônomos, muitas vezes à margem da conduçáo clerical, como o caso das beguinas, grupo reconhecido em Paris desde o século XIII, com proteção do rei (MILLER, 2014). Diante desse público, os letrados empenhados na instruçáo dos leigos e das mulheres fizeram dos livros e da escrita vernácula instrumentos de base para ordenar e conduzir a busca por práticas devotas mais introspectivas, pessoais e privadas, sendo o acesso aos livros facilitado pelo papel e em seguida pela imprensa, e também pelas bibliotecas comunais e paroquiais (BARBIER, 2005, p. 86; FEBVRE; MARTIN, 1992, p. 149; CHARTIER, 1989; CHIFFOLEAU, 2011, p. 111-113). Letrados como Cristina de Pisano recomendavam às damas boas leituras devocionais e alertavam as famílias para que lhes proibissem os livros mundanos e supérfluos, isto é, que não contribuíam para a virtude e para a salvação (LABARGE, 1997, p. 89-100).

O interesse crescente dos laicos por uma vida de ascese e oraçáo - que náo constituía uma novidade, mas se aprofunda no período - manifestou-se nas próprias irmãs do chanceler Gerson, para quem ele escreveu parte de seus textos de devoção em francês: mulheres sem casamento que, por decisão própria, passaram a se dedicar ao retiro devocional em casa; eram virgens que renunciaram ao matrimônio e uma delas viúva que não pretendia se casar novamente. O valor da "simplicidade" observado nelas, no que dizia respeito à sua pouca instrução, não impediu o letrado de fundar sua missão instrutiva no aprendizado das letras, aconselhando-lhes: "seria muito proveitoso que possais aprender a ler romance ${ }^{28}$, pois eu

\footnotetext{
${ }^{27}$ BNF, Département des manuscrits, Ms. Français 1841, f. 167. Tradução minha. No original: "Cette exposition se adressera plus especialment a linstruction de femme de religion ou de femme vivant en chastete hors mariage et qui est donnee en son cuer au seuice de Dieu".

${ }^{28}$ Roman. Romance, "língua vernácula". Dictionnaire du Moyen Français. Disponível em: http://www.atilf. $\mathrm{fr} / \mathrm{dmf} /$ definition/roman.
} 
vos enviarei livros de devoção, e vos escreverei com frequência com muita alegria e muito prazer" (GERSON, 1960, v. VII, p. 420). ${ }^{29}$ Os textos para elas continham ensinamentos básicos da catequese, como os mandamentos, os vícios e virtudes, os artigos de fé, com espaço para a prática privada da meditação e da oração. As prescriçôes visavam ordenar todo o tempo diário, como se elas de fato vivessem num monastério: deveriam ler textos religiosos todos os dias; "fazer oraçôes juntas algumas vezes, em especial após o jantar, para afastar as más melancolias e tentaçóes"; "dizer as oraçôes nas horas determinadas, como às matinas, às terças, às vésperas, ao pôr do sol e à meia-noite"; ouvir a missa o mais frequentemente possível, entre outras indicações. Em uma correspondência de 1399-1400, o teólogo compôs um guia de oraçôes para cada dia da semana, e, da mesma forma, o La Mendicité Spirituelle acompanhava-se de uma sequência de "oraçôes" e "meditaçôes" (STERPONI, 2008, p. 555559; KARNES, 2011).

Em meio à percepção geral de um mundo em desordem, acentuada pela escandalosa concorrência entre dois papas, alguns coetâneos eram admirados por sua imagem piedosa e plena entrega à oração, num período em que a santidade passava a associar-se cada vez mais à capacidade de contato íntimo e excepcional com Deus do que às obras corporais

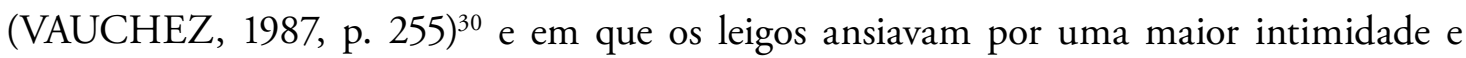
proximidade em relação às figuras sagradas dos santos, de Cristo e da Virgem. Pertencente ao círculo de amizades de Gerson e D’Ailly, o jovem cardeal Pedro de Luxemburgo (13691387) foi venerado como uma figura santa emblemática da fidelidade ao Papa de Avinhão, Clemente VII, e ao reino da França, justamente porque frequentava os monges celestinos e considerava sua dedicaçáo à oração de grande valia para a missão de pôr fim ao Cisma (GUENÉE, 1987, p. 177). A Chronique du Religieux de Saint Denis menciona o quanto ele "foi piedoso, casto e sóbrio [...] e que, ainda que estivesse sobre a Terra, já habitava o Céu" (1889, p. 479). ${ }^{31}$

Um texto para mulheres devotas atribuído ao cardeal circulou após sua morte com o título Les trois journées du chemin de pénitence, ou la Diète du salut, par Pierre de Luxembourg com um programa de oração. Nos conselhos desse texto, a devoção é entendida como o conteúdo afetivo dirigido a Deus, enquanto a oração é a sua forma: "esforçar-te-á para ter verdadeira devoção em oraçáo". Aproximando-se dos ensinamentos de Gerson sobre como se preparar para falar com Deus, o livreto expóe, por exemplo, "Dez coisas que ajudam a ter devoção", como a pureza de coração, a escolha do lugar mais adequado, a direção do pensa-

\footnotetext{
${ }^{29}$ Tradução minha. No original: “je auroye tres grant plaisir et seroit chose tres proufitable que vous peussiers aprendre a lire roumant, car je vou bailleroie livrez de devotion, et si vous escriproie tres souvent a moult grand joye et grand plaisir".

${ }^{30} \mathrm{~A}$. Vauchez assinala que a santidade dos séculos XIV e XV se baseava mais na revelação e na experiência mística, em detrimento da penitência e das boas obras.

${ }^{31}$ Traduçáo minha. No original: "combien il fut pieux, chaste et sobre [...] bien qu'il fût sur cette terre, il habitait déjà pour ainsi dire dans le ciel”.
} 
mento segundo determinados tópicos e temas, agir e sentir segundo as virtudes. ${ }^{32}$ Mas não apenas os religiosos e clérigos que se voltavam com mais afinco para a oração constituíam modelos, já que também muitos leigos eram por isso considerados dignos de elogio e imitação. Uma certa Agnes d'Auxerre é mencionada por Gerson em um de seus escritos para as irmãs, como exemplo (BROWN, 1987, p. 216) a ser imitado: "uma mulher muito devota" que, de forma muito amorosa e humilde - isto é, com a devida reverência e rebaixamento perante Deus -, colocava-se como uma mendicante, por meio da imaginaçáo, e pedia mentalmente dons espirituais aos santos, "fazendo uma procissáo [...], com ardor e diligência, para si e para os outros" (GERSON, 1960, v. VII, p. 172). ${ }^{33}$

No entanto, a plena entrega à oração e à devoçáo nem sempre configurava comportamentos exemplares e elogiosos, na visáo de algumas autoridades eclesiásticas. Com a multiplicação, no século XIV, das práticas devocionais nos centros urbanos do reino - das associações paroquiais laicas com supervisão clerical ou das comunidades informais que imitavam o modo de vida monástico, como as "beguinarias" -, amadurecia a reivindicação de uma relaçáo privilegiada e direta com Deus, expressa em escritos e gestos muitas vezes excessivos, sobretudo entre as mulheres, como os jejuns debilitantes e outras mortificaçôes que se acompanhavam de visōes (BOQUET; NAGY, 2008 p. 274; BOQUET; NAGY, 2015, p. $266-265,315) .^{34}$ Esses grupos atraíam a admiraçáo de alguns e a desaprovação de clérigos preocupados com a negligência dos sacramentos e obrigaçóes estabelecidas pela Igreja (ANDERSON, 2011, p. 158), ${ }^{35}$ bem como com a conformidade às virtudes da obediência, da moderação e da discrição - virtudes monásticas obrigatórias -, sendo seus integrantes acusados de seguir "apenas os próprios afetos, sem regra nem ordem, deixando de lado a lei de Cristo" (GERSON, 2008, p. 69). ${ }^{36}$

O papa Clemente V já havia se referido, no decreto de 1311-1312, Cum de Quibusdam, durante o Concílio de Viena, às mulheres chamadas beguinas - expressão que, na verdade, encobria uma ampla variedade de grupos -, que não prometiam obediência a ninguém, nem

\footnotetext{
${ }^{32}$ BNF, Département des manuscrits, f. 63. O texto também se encontra nos manuscritos: Ms. Français 1836 e Français 982.

${ }^{33}$ Tradução minha. No original: "une devote femme [...] pour ce que on m'avoit recite qu'elle queroit ses aumosnes de grace et fasoit sa procession de saint en saint tres diligement et ardenment pour soy et pour les autres [...] et se mettoit devant Dieu comme condempnee devant son juge, comme povre mendicant devant ung riche seigneur, comme malade devant son myre, [...] comme espouse desloyale devant son espous [...]". ${ }^{34}$ D. Boquet e P. Nagy associam essas práticas ao desenvolvimento de uma "devoção afetiva" marcada pela identificaçáo com o sofrimento de Cristo a partir do século XIII. Sobre a centralidade do corpo nessa devoção afetiva, ver também: Caroline Walker Bynum, The Resurrection of the Body in Western Christianity (p. 318-341).

${ }^{35}$ A partir de meados do século XIV, no período de explosão dos relatos dessas experiências espirituais entre os laicos, florescem os tratados teológicos dedicados à determinação da natureza de uma visáo ou revelaçáo, com o argumento de que tal exame deveria ser executado náo mais por quem vivenciava essas experiências, mas por avaliadores especializados, os teólogos.

${ }^{36}$ Tradução minha. No original: "ne suivant que leurs affect, sans règle ni ordre, laissant de côté la loi du Christ".
} 
professavam nenhuma regra e que, por isso, não poderiam ser consideradas religiosas. Denunciava que, conduzidas pela "insanidade", pregavam sobre os assuntos mais elevados, como a Trindade e a essência divina, introduzindo "opinióes contrárias à fé católica a respeito dos artigos da fé e dos sacramentos da Igreja" e que, por enganarem "muitas pessoas simples", "sob o véu da santidade", mereciam ser postas "sob suspeita" (TANNER, 1990, p. 374). ${ }^{37}$ Tal desconfiança acentuou-se ao longo do século XIV desde a condenação, em 1310, da beguina Margarida Porete e de seu livro em língua vernácula, Miroir des simples âmes annéanties, que tratava do êxtase místico resultante da união entre Deus e a alma, possível por meio apenas do amor, para além do intelecto e das normas sacramentais (BAILEY, 2003, p. 64-65). ${ }^{38}$ Malgrado sua proibição, o texto continuou sendo difundido entre os laicos ao longo de todo o século XIV e XV (HASENOHR, 1999, p. 1.349, 1.360), perpetuando assim a sedução de um caminho para Deus mais afetivo, íntimo e direto, à revelia dos preceitos clericais.

No mesmo sentido, as experiências de contato direto, afetivo e excepcional com Deus tornaram-se mais numerosas com a instauração do Cisma, e vinham dos mais variados pontos da Cristandade. Os teólogos consideravam suspeitas as experiências espirituais incomuns ou chamadas de "extraordinárias", resultantes de uma devoção demasiado apaixonada, como os relatos de visóes, revelaçóes, êxtases ou recebimento de estigmas, acompanhados do externar descomedido das emoçôes. Os que comunicavam publicamente suas visôes, êxtases e revelaçôes com frequência expressavam motivaçôes políticas, polarizando-se a favor do papado de Roma ou de Avinhão. Em defesa do retorno do pontífice a Roma, por exemplo, estavam as veneradas Catarina de Siena (1347-1380) e Brígida da Suécia (-1373), que tinham acesso direto ao Papa e enviavam cartas aos monarcas. Em contrapartida, do lado dos franceses, além de Pedro de Luxemburgo, despontavam figuras secundárias, porém muito cultuadas, como o clérigo Jean de Varennes (- 1396?) e a laica Maria Robine (-1399), que exaltavam o rei e o Papa Clemente VII. Os critérios de aceitação ou de reprovação desses casos esbarravam, da mesma forma, nas divisōes religiosas e políticas daquele cenário (VAUCHEZ, 1987, p. 254-255; VAUCHEZ, 1999; BLUMENFELD-KOSINSKI, 2006, p. 42-50, 77-78).

Diante desse quadro, em que muitos buscavam ter voz sobre questôes da Igreja a partir de convicçóes pessoais alegadamente inspiradas por Deus, clérigos renomados, como o pregador ibérico Vicente Ferrer, que então passava pela França em pregação, alertavam sobre o perigo de se buscar "as vias extraordinárias" de comunicação com Deus, o que poderia conduzir a ilusôes. "Aqueles que querem viver em devida submissão a Deus não devem desejar obter [...] visōes, revelaçôes ou sentimentos que estejam além da natureza e do estado ordi-

\footnotetext{
${ }^{37}$ Tradução minha. No original: "We have heard from trustworthy sources that there are some Beguines who seem to be led by a particular insanity. They argue and preach on the holy Trinity and the divine essence, and express opinions contrary to the catholic faith with regard to the articles of faith and the sacraments of the church. These Beguines this ensnare many simple people, leading them into various errors".

${ }^{38}$ A perseguição às beguinas marcou todo o século XIV, do Concílio de Viena, de 1311, ao Concílio de Constança, de 1414, sendo associadas ao antinomianismo, à dispensa da lei, da moralidade e dos sacramentos.
} 
nário dos que amam a Deus e lhe dirigem uma crença filial", alertava o valenciano, pois tais desejos que vão além do "ordinário" derivam do orgulho, da presunção e da vã curiosidade sobre as coisas de Deus (FERRER, 1866, p. 370-371) ${ }^{39}$. Também Jean Gerson aconselhava os interessados numa devoção interior a não ansiar pelo "extraordinário, mas desejar a via ordinária para a salvação, pois o orgulhoso será enganado" (GERSON, 1959, p. 33). ${ }^{40}$

\section{Diretrizes para o cotidiano devoto dos leigos}

Para contornar os erros e excessos devocionais, uma exigência ao se colocar em oraçáo, segundo os textos de direçáo espiritual elaborados por clérigos como o chanceler, consistia em desviar a atenção das agitaçóes mundanas e voltar-se com constância e profundidade às coisas eternas, em pensamentos e gestos. A solidão, ou o retiro espacial esporádico, bem como o silêncio, elementos fundadores da vida monástica, não deixavam de ser recomendados nesses escritos. Além de ajudar a fixar o pensamento na prece e na meditação, ao furtar-se dos olhares dos outros, evitava-se o orgulho, preocupação contundente num período em que se denunciava a vanglória resultante das exibiçóes de fé e de supostos contatos incomuns e diretos com Deus. Entre a lista de dez passos que ajudariam o cristão a ter devoção, isto é, a dirigir-se a Deus com afeto verdadeiro, o livro atribuído a Pedro de Luxemburgo prescreve justamente a chamada "busca do lugar secreto", ou seja, afastado de companhias, para que, ao rezar, o fiel náo fosse visto, e, desse modo, a vanglória ligada ao ato de se exibir como devoto não o impedisse de obter "o fruto de sua oração". ${ }^{41}$

A ideia do silêncio e solidão interiores - não referentes ao espaço objetivo -, por meio dos quais seria possível acessar Deus, era afirmada nos escritos místicos que começavam a ser compostos nas línguas vernáculas no século XIV (MCGINN, 1996, p. 206-208; MCGINN, 2001, p. 6-12; BLUMENFELD-KOSINSKI; ROBERTSON, 2002). Por meio dessa tópica, transpunha-se para o mundo dos laicos a possibilidade de vivenciar uma devoçáo interior sem abandonar o mundo, a vida doméstica e urbana. Meister Eckhart (1260-1328), um dos principais nomes dessa mística vernácula que ultrapassava o domínio dos teólogos monásticos, já considerava que aquele que carrega Deus dentro de si, no pensamento, o terá "em todos os lugares, nas ruas e entre as pessoas, não menos do que na igreja, no deserto

\footnotetext{
${ }^{39}$ Tradução minha. No original: “[...] c'est de ne point désirer arriver par la prière [...]ou par d'autres oeuvres de perfection, à avoir de révélations ou des sentiments qui soient au-dessus de la nature et de l'état ordinaire de ceux qui aiment Dieus et le craginent d'une crainte filiale. Car ces désirs ont toujours leur racine et leur fondement dans une pensée d'oirgueil et de présomption."

${ }^{40}$ Tradução minha. No original: "Advise such a one not to long for the extraordinary, but to desire the ordinary way of salvation, for he speaks truly who that pride deserves to be deceived".

${ }^{41}$ BNF, Département des manuscrits, Ms. Français 1836, f. 17. Tradução minha. No original: "le fruit de son oraison".
} 
ou na cela" (2009, p. 490) ${ }^{42}$ e, com isso, tornava possível a busca de conexão com Deus em qualquer ambiente. Jean Gerson, por sua vez, ao ensinar a contemplação aos simples, também explanou a noção de silêncio e solidão interiores, considerados mais importantes do que o retiro corporal, referindo-se a um estado do pensamento e do coração. Para ele, "segundo diversos estados e condiçóes", isto é, leigos ou clérigos, poder-se-ia "encontrar seu lugar secreto para estar em paz e silêncio", já que "o principal segredo e silêncio deve[m] estar dentro da alma, mais do que do lado de fora", quer dizer, "quando a alma expulsa para fora de si [...] toda preocupação mundana” (GERSON, 1960, v. VII, p. 32). ${ }^{43}$ Assim, a vida contemplativa, isto é, dedicada à oração, deixava, na visão desses letrados, de ser apanágio de monges e clérigos.

Porém, atento aos erros devocionais de seus coetâneos, que denunciava e pretendia combater para salvaguardar a ortodoxia das práticas religiosas, o chanceler apontou antigos preceitos monásticos que advertiam sobre os perigos da solidão: na Montaigne de Contemplation, recorreu a Sêneca ao aconselhar que não se buscasse permanecer só por muito tempo (GERSON, 1960, v. VII, p. 27). No entanto, recorda que o próprio Sêneca e também os santos louvaram a solidáo e a ociosidade, como forma de servir a Deus, concluindo que a busca bem-sucedida da solidão dependia da compleição de cada um e que os feitos memoráveis dos santos deveriam ser admirados humildemente em vez de imitados. Reforçava, portanto, os perigos da solidáo exterior para aqueles inexperientes e desprovidos de capacidade de resistir às tentaçôes do mundo, bem como a dimensáo interior do retiro, referindo-se aos que, mesmo estando "seules de corps", sofriam pesada companhia dentro de si mesmas, onde ocorrem "grandes ruídos e palavrórios". Entre os excessos de ascetismo denunciados por Gerson, estava um fenômeno urbano comum no reino da França no século XIV, principalmente entre mulheres: a reclusão voluntária, o confinamento em celas adjacentes a igrejas, hospitais e leprosários. Dizia ele que as reclusas "desapontaram-se miseravelmente, porque quiseram voar antes que tivessem asas" (GERSON, 1960, v. VII, p. 27-28). ${ }^{44} \mathrm{~A}$ tópica dos perigos da solidão, nesse sentido, alertava para os riscos da arrogância por parte daqueles que, sem vocação ou preparo, confiavam apenas em si próprios, abrindo mão dos conselhos e das repreensôes de outrem para se erigir moral e espiritualmente (WEBB, 2007, p. xiv).

Por isso, o teólogo de Paris aconselhava suas irmãs sobre a importância dos labores corporais, como o cultivo das atividades domésticas e da penitência, antes de poderem "estar sós e em segredo" e se dedicarem por completo "a pensar em Deus à maneira das eremitas

\footnotetext{
${ }^{42}$ Tradução minha. No original: "[...] everywhere, in the street or among people just as much as in church or in the desert or in a cell".

43 Tradução minha. No original: “[...] le principal secret et la silence doyvent ester par dedens l'ame plus que dehors; c'est a dire que l'ame boute hors de soi [...] toute cure mondaine [...]”.

${ }^{44}$ Tradução minha. No original: "[...] ont este deceuz miserablement, car il voloient voler aincois qu'il eussent elles ailes".
} 
ou reclusas". ${ }^{45}$ Diante dos riscos de orgulho e desobediência, ao se ensinar aos leigos o abandono das ocupaçóes mundanas para adentrar a vida de oração, sem deixar as ocupaçôes moderadas (GERSON, 1960, v. VII, p. 21; CASAGRANDE; VECCHIO, 2003, p. 129137), diretores como Gerson conciliavam de alguma forma a vida dos laicos ao princípio do contemptus mundi, bem como a via ordinária ou sacramental para a salvação e o diálogo interior com Deus. A atratividade da solidáo interior para os leigos e a reserva que cercava a reclusão, todavia, não impediam que os escritos de direção espiritual oferecessem sugestôes quanto ao lugar e as disposiçóes corporais mais apropriadas e eficazes para o fiel comunicar a Deus seu afeto genuíno e a obtenção, em retorno, dos dons espirituais de que necessitava.

O governo dos pensamentos tinha um papel central nessa busca da intimidade e da introspecção, fundamentava o ato de alojar-se dentro de si, de "retourner en soi", nos termos de Gerson, e deveria guiar todo o percurso de oração, mas as deliberaçóes corporais e espaciais não deixavam de ter seu peso. Aconselhava Gerson aos iniciantes - ou àqueles que ainda não tivessem a capacidade de encontrar silêncio e "retirar-se em si mesmos" estando em companhia de outrem, o que demandaria tempo, prática e "grande perfeiçáo" - que a escolha cuidadosa de um lugar exterior poderia ser proveitosa, já que "para ter o segredo e o silêncio da alma por dentro, é conveniente buscar o segredo e o silêncio por fora" (GERSON, 1960, v. VII, p. 32-33). ${ }^{46}$ Considerou, assim, a variedade de posturas e espaços válidos segundo a compleição física e afetiva (CASAGRANDE, 2013) ${ }^{47}$ de cada um: "as florestas" ou "os desertos"; "os segredos dos campos"; "os locais secretos das igrejas ou de suas próprias casas", enumerando algumas posturas, como ajoelhar-se, sentar-se, inclinar-se, sendo o repouso preferível ao movimento e a noite a hora mais cômoda (GERSON, 1960, v. VII, p. 32-33).

A figura solitária da Virgem Maria em oração constituía o modelo capital de devoção interior nesses escritos para as mulheres devotas. No sermáo Poenitemini, proferido na igreja da abadia de Saint-Antoine-des-Champs, em janeiro de 1403, Gerson descreveu as açôes da Virgem logo após a morte de Jesus. $\mathrm{Na}$ ocasião, ela vivencia a dor não pela exibição, mas pelo recolhimento e interiorização em seu quarto, afastada dos olhares dos outros e diante apenas do seu oratório pessoal, esse elemento do mobiliário doméstico que se tornava mais comum no tempo do chanceler: (WEBB, 2007, p. 125) "Nossa Senhora", explica, "retirou-se sozinha para seu pequeno quarto e seu oratório secreto, onde deu graças e encomendou a Deus a guarda de São João, que se retirou em seu pequeno quarto separado. [...] Não saiu do lugar, nem falou a ninguém" (GERSON, 1960, v. VII/2, p. 518)..$^{48}$ Cristina de Pisano

\footnotetext{
${ }^{45}$ Tradução minha. No original: "[...] vous puisssiez vous tenir seules et secretes et du tout vous donner a penser em Dieu en guise d'ermites ou recluses".

${ }^{46}$ Tradução minha. No original: "Vrai est que a avoir le segret et la silence de l'ame par dedans pourfite querir segret et silence par dehor"”.

${ }^{47}$ Relativo aos afetos ou às paixóes da alma.

${ }^{48}$ Tradução minha. No original: "[...] En parfin Nostre Dame se retrahi seulette en sa chambrette et en son oratoire secret apres que graces furent dictes et qu'elle eut commande a Dieu sant Jehan, sa bonne garde, qui se retrahi en une autre chambrette a part. [...] et ne se party d'un lieu et ne parla point a autrui".
} 
também incorporava o modelo da seulette, a mulher solitária contemplativa que, por meio de sua oração, atuava na solução dos problemas do mundo (WALTERS, 2012, p. 133, 136, 142). Cada vez mais preponderante desde o século XII, a figura de Maria fundamentou a construção das devoçôes pessoais e privadas, não apenas como objeto de culto e veneração, mas também como modelo para a imitação (FULTON, 2002, p. 202), com maior ênfase, nos séculos XIV e XV, em seus traços humanos e nos vestígios do sagrado incrustados na vida doméstica, o que promovia uma maior identificação por parte dos fiéis (RUBIN, 2009, p. $89,96,104)$.

O quarto aparecia como lugar privilegiado nas referências às vidas de pessoas devotas, como a laica Catarina de Siena e outas figuras mais ou menos insignes (WEBB, 2007, p. 125). O desenvolvimento das modalidades de vida religiosa doméstica nos séculos XIV e XV contribuía para fazer desse espaço da casa o principal lugar para os laicos buscarem uma relação mais íntima com Deus, retiro que geralmente conciliavam com a ida regular à igreja ou com as obras de caridade. O livro de devoção da rainha Joana d'Évreux (13101371) prescrevia: "se não estiveres fora e se estiveres em tua casa, mantém-te o mais reclusa que puderes em teu quarto, pois em seu quarto foi saudada a gloriosa Virgem Maria"; recomendava também a leitura de algum bom texto e a execuçáo de "alguma obra salutar em casa”, e que se evitassem a mãe, os irmãos e irmãs. ${ }^{49}$ No mesmo sentido, o supracitado Avisements destacava: "quando quiseres orar a teu pai celestial, entra em teu quarto [...] e reza a Ele em segredo", que dizer, de forma solitária. ${ }^{50}$ A casa e o quarto configuravam, pois, os ambientes mais seguros para essa devoção laica ansiosa por formas mais íntimas de diálogo com Deus e que se queria supervisionada e distante do retiro considerado orgulhoso das beguinas e reclusas.

Os manuais de oração em língua vernácula e o diálogo mais íntimo com Deus ganhavam espaço no cotidiano dos leigos também na medida em que, nos séculos XIV e XV, os lares passavam a acomodar mais possibilidades materiais para o desenvolvimento da oração privada. A proliferaçáo dos livros portáteis de oraçáo, para serem lidos silenciosamente durante a missa ou em casa, acompanhava-se da consolidação do uso de expressóes sugerindo o contato ocular com o texto (como a ênfase no verbo veoir) e uma leitura a ser feita "com o coraçáo", quieta, bem como de um vocabulário para se referir ao ato de estar consigo, como "privauté" e "secret". A leitura silenciosa e privada começou, dessa maneira, a fundamentar e a incentivar o cotidiano devoto doméstico de leigos como as irmãs do chanceler Gerson. Recorriam-se, além dos livros, a capelas particulares, amuletos, rosários, altares móveis, imagens impressas e miniaturas em madeira, para adornar os ambientes reservados à oração

\footnotetext{
${ }^{49}$ BNF, Département des manuscrits, Ms. BNF, Français 1802, f. 81/69. Tradução minha. No original: "Se tu n'est hors et tu es a ton ostel, si te tient le plus reclusement que tu pouras en ta chambre, car en sa chambre fu la glorieuse vierge saluee [...]".

${ }^{50}$ BNF, Département des manuscrits, Ms. Fr. 13204, f. 176. Tradução minha. No original: “[...] quant tu vouldras prier ton pere celestial entre dedans ta chambre et ainsi prie ton pere en secret".
} 
(FAURE, 2001; BOZOKY, 2001); elementos mais corriqueiros não apenas entre os grandes, mas nas famílias ascendentes. Essa devoção doméstica importava padróes e modelos conhecidos, monásticos, e constituía não uma alternativa à religião pública, mas uma extensão desta, onde os seus gestos e palavras eram reafirmados (WEBB, 2007, p. 97, 122, 123, 131).

\section{Conclusão}

O debate que se acende no período do Cisma e avança ao longo do século XV sobre as formas consideradas legítimas e as julgadas errôneas de devoção apontava para a necessidade de regrar a comunicação pessoal com o sagrado, dando pistas sobre a pertinência de se formular novos ensinamentos sobre a oração e a devoção no reino da França, onde iniciativas de compor livros em língua vernácula para os leigos ganhavam corpo. Apesar de veicularem tópicos como a contemplação, que, em tese, propunham uma relação direta e "extraordinária" com o sagrado e avançavam para além do repertório instrutivo básico ou "ordinário" necessário a todos os fiéis - a saber, os sacramentos, os mandamentos, as virtudes, os artigos de fé, as oraçôes principais -, tais textos de oração resguardavam de algum modo a adequação ao que podemos traduzir por uma devoção humilde, obediente, discreta e moderada, formulada por clérigos que se mostravam conservadores dos parâmetros ascéticos tradicionais e do valor dos sacramentos. ${ }^{51}$ Os escritos aqui analisados ilustram, em suma, a preocupação de que essa "devoção interior" fosse ensinada de uma maneira que não negligenciasse a ênfase na obrigação de todo fiel de respeitar os sacramentos e de agir segundo os preceitos fundamentais da fé cristã.

\section{Documentação primária}

\section{Manuscritos}

BIBLIOTHÈQUE NATIONALE DE FRANCE. Département des manuscrits, Ms. Français 926.

BIBLIOTHÈQUE NATIONALE de France. Département des manuscrits, Ms. Français 13204.

\footnotetext{
${ }^{51}$ Nesse período de crença acentuada nos meios diretos e milagrosos de acesso ao divino, emergia a discussão sobre a eficácia dos sacramentos ministrados por clérigos pecadores - ao lado do desprezo dos sacramentos já externado pelos grupos heréticos, como os "Espírito Livre" ou as beguinas -, o que levou autoridades a reforçarem a recepção dos sacramentos, afirmando sua obrigatoriedade não obstante a conduta daqueles que os administravam.
} 
BIBLIOTHÈQUE NATIONALE DE FRANCE. Département des manuscrits, Ms. Français 1836.

BIBLIOTHÈQUE NATIONALE DE FRANCE. Bibliothèque de l'Arsenal, Ms. Français 982.

BIBLIOTHÈQUE NATIONALE DE FRANCE. Département des manuscrits, Ms. Français 13204.

LIVRE DE dévotion de Jeanne d'Évreux. Bibliothèque Nationale de France. Département des manuscrits, Ms. Français 1802.

LIVRE DE la moralité de nobles hommes et des gens de peuple, selon le jeu des eschecqs, translaté de latin [de Jacques de Cessoles] en franczois, par frère Jehan de Vignay, hospitalier de l'ordre de Hault Pas. Bibliothèque Nationale de France. Département des manuscrits, Ms. Français 24437.

\section{Ediçôes}

AUGUSTINE. On the trinity. Books 8-15. Cambridge University Press, 2002.

GERSON, Jean; BOLAND, Paschal. The concept of Discretio Spirituum in John Gerson's 'De probatione Spirituum' and 'The distinctione verarum visionem a falsis'. Washington: The Catholic University of America, 1959.

GERSON, Jean; BOLAND, Paschal. Oeuvres complètes. Introduction, texte et notes par Mgr Glorieux. V. VII. Paris: Desclée, 1960.

GERSON, Jean; BOLAND, Paschal. Early works. Tradução Brian Patrick McGuire. New York: Paulist Press, 1998.

GERSON, Jean; BOLAND, Paschal. Sur la théologie mystique. Textes introduits, traduits et annotés par Marc Vial. Paris: Vrin, 2008.

DE ROY, Guy. Le doctrinal de sapience (Le doctrinal des simples gens). Lyon, 1485, p. 1.

LE ROY, François. Le livre de la femme forte et vertueuse. Paris: Simon Vostre, s/d.

TANNER, Norman P. (ed.) Decrees of the Eccumenical Councils. Volume One: Nicaea I to Lateran V. London/Washington: Sheed \& Ward e Georgetown University Press, 1990.

TRAITÉ DE la vie spirituelle par S. Vincent Ferrier de l'ordre des frères-précheurs avec des commentaire sur chaque chapitre par la Vén. Mère Julienne Morell, religieuse du même ordre. Poitiers: Henri Oudin, 1866.

THE COMPLETE works of Meister Eckhart. Trad. Maurice O'C Walshe. Introd. Bernard McGinn. New York: The Crossroad Publishing Company, 2009. 


\section{Referências}

ANDERSON, Wendy Love. The discernment of spirits: assessing visions and visionaries in the Late Middle Ages. Tübingen: Mohr Siebeck, 2011.

BAILEY, Michael. Battling demons: witchcraft, heresy, and reform in the Late Middle Ages. Pennsylvania State University Press, 2003.

BARBIER, Frédéric. História del libro. Madri: Alianza, 2005.

BLUMENFELD-KOSINSKI, Renate; ROBERTSON, Duncan; WARREN, Nancy. B. The vernacular spirit: essais on medieval religious literature. New York: Palgrave, 2002.

BLUMENFELD-KOSINSKI, Renate. Poets, saints, and visionaries of the Great Schism, (1378-1417). Park: The Pennsylvania State University, 2006.

BLUMENFELD-KOSINSKI, Renate; PETKOV, Kiril (eds.) Philippe de Mézières and his age. Piety and politics in the fourteenth century. Leiden/Boston: Brill, 2012.

BOZOKY, Edina. Les moyens de la protection privée. Cahiers de recherches médiévales, 8, 2001, mars 2008 .

BROWN, D. Catherine. Pastor and laity in the theology of Jean Gerson. London: Cambridge University Press, 1987.

BYNUM, Caroline Walker. The resurrection of the body in Western Christianity, 200-1336. New York: Columbia University Press, p. 318-341, 1995.

CASAGRANDE, Carla; VECCHIO, Silvana. A mulher sob custódia. In: DUBY, Georges; PERROT, Michelle. (dir.) História das mulheres no Ocidente. Porto: Afrontamento, 1990.

CASAGRANDE, Carla; VECCHIO, Silvana. Histoire des péchés capitaux au Moyen Âge. Paris: Flammarion, Aubier, 2003.

CASAGRANDE, Carla; VECCHIO, Silvana. Les passions, la mystique, la prière: affectivité et dévotion dans la pensée de Jean Gerson. Revue Mabillon, n.s, t. 24, 2013.

CHARTIER, Roger; MARTIN, Henri-Jean. Histoire de l'édition française. Fayard/Promodid, 1989.

CHIFFOLEAU, Jacques. Les confréries, la mort et la religion en Comtat Venaissin à la fin du Moyen Âge. In: Mélanges de l'École française de Rome. Moyen-Age, Temps Modernes, tome 91, n. 2, p. 785-825, 1979.

CHIFFOLEAU, Jacques. La violence au quotidien. Avinhão au XIVe siècle d'après les registres de la Cour temporelle. In: Mélanges de l'École Française de Rome. Moyen-Age, Temps Modernes, tome 92, n. 2, p. 325-371, 1980.

CHIFFOLEAU, Jacques. La religion flamboyante. France (1320-1520). Point, 2011.

DAILEADER, Philip. Local experiences of the great western schism. In: ROLLO-KOSTER, 
Joëlle; IZBICKI, Tomas M. (eds.) A companion to the great western schism. Leiden/ Boston: Brill, 2009.

DUBY, Georges; PERROT, Michelle (dir.). História das mulheres no Ocidente. Porto: Afrontamento, 1990.

FAURE, Philippe. Introduction. Cahiers de recherches médiévales, 8, 2001, mars 2008.

FEBVRE, Lucien; MARTIN, Henri-Jean. O aparecimento do livro. São Paulo: Universidade Estadual Paulista/ Hucitec, 1992.

FISHER, Jeffrey. Gerson's mystical theology: a new profile of its evolution. In: MCGUIRE, Brian. P. A companion to Jean Gerson. Leiden/Boston: Brill, 2006.

FULTON, Rachel. From judgement to passion: devotion to Christ and the Virgin Mary (8001200). New York: Columbia University, 2002.

GRANT, Patrick. Literature of mysticism in western tradition. London: The Macmillan, 1983. GUENÉE, Bernard. Entre l'Église et l'État: quatre vies de prélats français à la fin du Moyen Âge. (XIIIe-XVe siècle). Paris: Gallimard, 1987.

HARRINGTON, L. Michael. (ed.) A thirteenth century textbook of Mystical Theology at the University of Paris. Paris/Leuven/Dudley: Peeters, 2004.

HASENOHR, Geneviève. La tradition du Miroir des simples âmes au XVe siècle: de Marguerite Porète $(\dagger 1310)$ à Marguerite de Navarre. In: Comptes rendus des séances de l'Académie des Inscriptions et Belles-Lettres, 143e année, n. 4, 1999.

HASENOHR, Geneviève. Textes de devotion et lectures spirituelles en langue romane (France, $X I I^{\mathrm{e}}-X V I^{\mathrm{e}}$ siècle). Turnhout: Brepols, 2015.

KARNES, Michelle. Imagintation, meditation and cognition in the Middle Ages. Chicago/ London: University of Chicago Press, 2011.

KENNEY, John Peter. Contemplation and classical Christianity. A study in Augustine. Oxford University Press, 2013.

LABARGE, Margaret Wade. A medieval miscellany. Ottawa: Carleton University Press, 1997.

LE GOFF, Jacques; SCHMITT, Jean-Claude. Dicionário temático do Ocidente Medieval. São Paulo: EDUSC, 2006.

MCGINN, Brian. The Changing Shape of Late Medieval Mysticism. Church History 65, n. 2, p. 197-219, 1996.

MCGINN, Brian. Meister Eckhart and the beguine mystics: Hadewijch of Brabant, Metchild of Magdeburg and Marguerite Porete. New York: Continuum, 2001.

MCGUIRE, Brian. P. A companion to Jean Gerson. Leiden/Boston: Brill, 2006.

MILLER, Tanya Stabler. The beguines of medieval Paris: gender, patronage and spiritual 
authority. Philadelphia: University of Pennsylvania, 2014.

NAGY, Piroska. Au-delà du verbe. L'efficacité de la prière individuelle au Moyen Âge entre âme et corps. In: COTTIER, Jean-François. La prière en latin, de l'Antiquité au XVIe siècle: formes, évolutions, significations. Turnhout: Brepols Publishers, 2006.

NAGY, Piroska. BOQUET, Damien. Les sujets des émotions au Moyen Âge. Paris: Beauchesne, 2008.

NAGY, Piroska. Sensible Moyen Âge: une histoire des émotions dans l'occident médieval. Paris: Seuil, 2015.

PASCOE, Louis B. Jean Gerson: principles of Church Reform. Leiden: E. J. Brill, 1973.

PETRY, Ray. C. Late medieval mysticism. Louisville: Westminster, 1957.

POST, Regnerus R. The modern devotion. Confrontation with Reformation and Humanism. Leiden: E. J. Brill, 1968.

ROLLO-KOSTER, Joëlle; IZBICKI, Tomas M. (eds.) A companion to the great western schism. Leiden/ Boston: Brill, 2009.

RUBIN, Miri. Emotion and devotion: the meaning of Mary in medieval religious cultures. Budapest/New York: Ceu Press, 2009.

RÜEGG, Walter. Uma história da universidade na Europa. v. 1. Lisboa/Porto: Imprensa Nacional Casa da Moeda/ Conselho de Reitores, 1996.

SCHMITT, Jean-Claude. O corpo, os ritos, os sonhos, o tempo. Ensaios de antropologia medieval. Petrópolis: Vozes, 2014.

STERPONI, Laura. Reading and meditation in the Middle Ages: lectio divina and books of hours. In: STERPONI, L. The spirit of reading: practices of reading sacred texts. Special issue of Text \& Talk, v. 28, n. 5, p. 667-689, 2008.

STUMP, Phillip H. The Council of Constance (1414-18) and the end of the Schism. In: ROLLO-KOSTER, Joëlle; IZBICKI, Tomas M., 2009.

TEODORO, Leandro A. (ed.). Guias dos costumes cristãos: os primeiros opúsculos pastorais em língua portuguesa. São Paulo: Unifesp, 2019.

VAUCHEZ, André. Les laïcs au Moyen Âge. Paris: Cerf, 1987.

VAUCHEZ, André. Saints, prophètes et visionnaires. Le pouvoir surnaturel au Moyen Age. Paris: Albin Michel, 1999.

VAUCHEZ, André. Avant-propos. Cahiers de recherches médiévales, 8, 2001, mars 2008.

VON MOOS, Peter. Occulta cordis. Contrôle de soi et confession au Moyen Âge, I. Formes du silence. Médiévales, n. 29, p. 131-140, 1995.

WALTERS, Lori. Le vieil solitaire and the seulette: contemplative solitude as political theology in Philippe de Mézières, Christine de Pizan, and Jean Gerson. In: BLUMENFELD- 


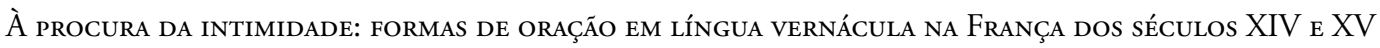

Letícia Gonçalves Alfeu de Almeida

KOSINSKI, Renate; PETKOV, Kiril (eds.). Philippe de Mézières and his age. Piety and politics in the fourteenth century. Leiden/Boston: Brill, 2012.

WEBB, Diana. Privacy and solitude in the Middle Ages. New York/London: Continuum/ MPG Books, 2007. 